$\infty$

0

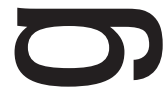

-

ת

1

$\longrightarrow$ 



\title{
A MEDIAÇÃO dO ENSINO-APRENDIZAGEM DE GEOGRAFIA, POR CHARGES, CARTUNS E TIRAS DE QUADRINHOS
}

\author{
LA MÉDIATION DE L'ENSEIGNEMENT-APPRENTISSAGE DE LA GÉOGRAPHIE PAR DES \\ CHARGES, CARTUNS ET BANDES DESSINÉES
}

\author{
Eunice Isaias da Silva - CEPAE/UFG \\ euniceisaias@gmail.com \\ Lana de Souza Cavalcanti - UFG \\ Is.cavalcanti@uol.com.br
}

\section{Resumo}

Esse artigo é resultado da divulgação de parte de um estudo realizado para a pesquisa de doutorado de Geografia do Instituto de Estudos Sócioambientais da Universidade Federal de Goiás (lesa-UFG). 0 título proposto para esse trabalho é "Charges e tiras de quadrinhos como mediação para 0 estudo de cidade na Geografia escolar". A pretensão é contribuir com uma discussão sobre o potencial dessa produção cultural do cotidiano, em mediar a relação ensino-aprendizagem de conteúdos geográficos, principalmente relativos à cidade. A idealização de se realizar essa investigação foi a partir da constatação do interesse demonstrado pelos alunos por meio da experiência observada em trabalhos realizados nas aulas de $\mathrm{Ge}$ ografia do Ensino Básico no Centro de Pesquisa Aplicada à Educação (Cepae/UFG). Em uma abordagem conceitual faz-se uma exposição do que tem sido discutido atualmente sobre esse tema, no ensino de uma forma geral e em especial na Geografia escolar.

Palavras-chave: linguagem alternativa no ensino, recursos didáticos, geografia escolar

\section{Résumé}

Cet article est le résultat de la diffusion d'une partie d'une étude réalisée pour la recherche de doctorat en Géographie de I'Institut des Études Socio-environnementales de l'Université Fédérale de Goiás (lesa-UFG). Le titre proposé pour ce travail est "Charges et bandes dessinées comme médiation pour l'étude de la villee en Géographie scolair". La prétention est de contribuer à une discussion sur le potentiel de cette production culturelle du quotidien comme médiation du rapport enseignement-apprentissage de contenus géographiques, principalement de ceux qui concernent les villes. L'idée de la réalisation de cette enquête est originée de la constatation de l'intérêt montré par les élèves à travers l'expérience observée dans des travaux réalisés dans les classes de Géographie du premier cycle d'enseignement au Centre de Recherche Appliqueé à l'Éducation (Cepae- UFG). Dans une approche conceptuelle est faite une exposition de ce qui est discuté actuellement sur ce thème-ci, dans l'enseignement d'une forme générale et plus spécifiquement en Géographie scolaire.

Mots-clés: langage alternatif dans l'enseignement, ressources didactiques, géographie scolaire

\begin{tabular}{|l|c|c|c|c|c|c|}
\hline Boletim Goiano de Geografia & Goiânia - Goiás - Brasil & v. 28 & n. 2 & p. 141-156 & jul. / dez. & 2008 \\
\hline
\end{tabular}





\section{Introdução}

A proposição da pesquisa sobre metodologia de ensino de Geografia com a mediação de quadrinhos, cartum e charge é pensada para trabalhar com algo que, entre outras características, seja instigante, criativo, crítico, questionador, podendo com humor e aprofundamento científico servir a propósitos didático-pedagógicos. Esta escolha é fruto da experiência profissional, ao se observar que vários livros didáticos de Geografia utilizam charges, cartuns e tiras de quadrinhos para ilustrar conteúdos específicos dessa disciplina, pelo entendimento de que podem propiciar uma relação ensino-aprendizagem mediada pela análise questionadora e ainda, pelo interesse demonstrado por parte dos estudantes. E no caso da Mafalda, talvez a mais utilizada, principalmente em livros de Língua Portuguesa, percebeu-se que, se houvesse um levantamento prévio de suas várias possibilidades de uso, no ensino de Geografia, poderia ser mais apropriado na prática pedagógica. A adequada utilização desses materiais, aliada a uma proposta de estudo consistente e bem fundamentada, proporciona uma aprendizagem com maior senso crítico, reforçada pelo potencial educativo desses recursos.

Encontram-se tiras de quadrinhos da Mafalda com temas geográficos em livros didáticos de Geografia e também, algumas em livros de Língua Portuguesa. E ao ter um breve contato com o livro “Toda Mafalda”, despertou-se uma inquietação com a percepção de que há muito mais para ser usado para motivar e mediar com profundidade e análise crítica os debates de temas tratados nas aulas de Geografia.

O cartum, a charge e os quadrinhos retratam muitas situações de conteúdo geográfico que podem ser analisadas em escalas local, regional, nacional ou mundial. Considerando que existem poucas obras didáticas sobre a Geografia do município de Goiânia e mesmo do Estado de Goiás, e com a intenção de procurar superar um pouco esta lacuna, tornou-se importante analisar, além da Mafalda, outras manifestações mais locais. Para tanto, optou-se por verificar essas representações publicadas diariamente no jornal - O Popular - que possui maior divulgação no Estado.

Mafalda e sua turma são personagens conhecidos praticamente no mundo todo, criados por Quino, artista argentino, trata de assuntos mundializados, dos quais grande parte oferece condições de abordagem em Geografia Geral com possibilidades de determinadas adaptações para a escala nacional. Mas e o regional, o local? Goiás? Goiânia? Daí a idéia de se procurar essas outras escalas de análise geográfica nos quadrinhos do Katteca, que 
é um índio, criação de Britvs (pseudônimo de João Luis Brito de Oliveira), que representam fatos e elementos da sociedade brasileira e ainda, averiguar essas condições nas charges de Jorge Braga e do Mariosan, todos veiculados no jornal "O Popular", da cidade de Goiânia-Goiás. Com a realização dessa tarefa, se contemplarão aspectos fundamentais para a Geografia escolar, com o intuito de tornar esse estudo mais consistente, por meio da crítica coerente e aprofundada.

Observa-se que a maioria dos alunos gosta desse tipo de recurso didático, quando usado de forma complementar aos conteúdos estudados. Motiva a discussão e reflexão, tornando a aula mais receptiva e agradável e, principalmente, estimula uma leitura mais apurada da realidade vivida e a desmistificação da ideologia que permeia as relações sociais e políticas do mundo. Contudo, os professores nem sempre têm acesso ou disponibilidade de tempo para enriquecer suas aulas com este material, e esta proposta de pesquisa é uma tentativa de fornecer algumas possibilidades aos vários professores de Geografia do Ensino Básico e até mesmo do Ensino Superior, além de ser uma contribuição pessoal ao trabalho com ensino de Geografia no Centro de Pesquisa Aplicada à Educação (Cepae-UFG).

\section{Quadrinhos e ensino}

As revistas em quadrinhos costumam ser as primeiras leituras das crianças e continuam existindo na vida de alguns adultos. Percebe-se que tem aumentado o uso de tiras de quadrinhos, charge, cartum no ensino escolar, como também, em muitas provas de processo seletivo e que este tipo de abordagem faz parte da rotina de quase todas as pessoas, pois é bastante divulgada pelos meios de comunicação. Como é uma leitura agradável, envolvente e a maioria dos alunos acha prazeroso esse tipo de atividade, pressuposto, que se torna um facilitador para empreender uma discussão com um certo rigor científico, a partir de elementos do cotidiano.

Sem muita preocupação com a distinção entre cartum, charge e quadrinhos, como salienta Moretti (2006) o qual afirma que "não é fácil estabelecer uma diferença definitiva entre essas formas de arte” ( p. 1). Enquanto a charge utiliza a caricatura, o cartum raramente a contém, ele surgiu após a charge e seus personagens são criações do autor. Moretti diz ainda que “a forma do cartum é universal, atemporal e não-perecível” (2006, p. 2), 
enquanto a charge, ao contrário, geralmente é datada e localizada geograficamente. Normalmente, ambos fazem críticas sociais e políticas. Já os quadrinhos são mais versáteis, com uma perspectiva mais ampla, podem ser críticos, esotéricos, infantis, adultos.

Os quadrinhos têm personagens e elenco fixos, narrativa seqüencial em quadros numa ordem de tempo onde um fato se desenrola através de legendas e balões com texto pertinente à imagem de cada quadrinho. A história pode se desenvolver numa tira, numa página ou em duas ou em várias páginas (revista ou álbum). É óbvio que para uma história ser em quadrinhos ela precisa ter no mínimo dois quadrinhos (ou cenas). A tira diária é uma exceção, pois, às vezes, a história pode ser muito bem contada em 1 (sic) só “quadrinho" (o espaço da própria tira), mas isso não a torna um Cartum, apesar da proximidade. (Moretti, 2006, p.20. Grifos do autor.)

Notamos que as personagens Mafalda, Katteca e alguns trabalhos de Mariosan estão mais bem caracterizados na categoria de tiras de quadrinhos, enquanto as obras de Jorge Braga e às vezes de Mariosan se aproximam mais da charge, e é assim que serão denominados nesse estudo.

Esse material, para tornar-se um recurso didático mais acessível aos professores, necessita ser lido, selecionado e organizado por temas, o que facilitaria a sua divulgação e utilização. Foi assim que surgiu o interesse de se pensar nessa proposta de pesquisa.

\section{Outras linguagens para se estudar Geografia}

Atualmente, é indiscutível que a produção cultural possa ser um importante aliado do ensino escolar. Vários conteúdos da escola seriam mais bem compreendidos e internalizados com a utilização de obras literárias, artes plásticas, canções, peças teatrais, imagens, gibis, dentre outros. Entende-se, também, ser papel da escola estimular e socializar o conhecimento das várias formas de expressão cultural, orientando e fornecendo elementos para uma análise crítica da realidade.

Estes instrumentos auxiliares necessitam ser antecipadamente selecionados, conforme os objetivos definidores das ações educativas, a fim de motivar, aprofundar o estudo e sua sistematização, por meio de atividades artísticas e lúdicas, que permitem a avaliação acurada do objeto analisado.

O mundo atual se sobrecarrega de comunicação e informação, bastante facilitadas pela tecnologia, nesse aspecto, Kenski (2005) destaca que 
"na verdade somos todos da geração alfabética - da aprendizagem por meio do texto escrito, da leitura do artigo. Somos analfabetos para a leitura das imagens, dos sons" (p.132). A realidade cotidiana mudou e é necessário estar atento, pois a clientela da escola também não é a mesma, as mudanças ocorrem com muita rapidez. Kenski continua argumentando que "para esses alunos, por exemplo, o professor não é mais a única, nem a principal, fonte do saber. (...) Estes alunos estão acostumados a aprender através dos sons, das cores; através das imagens fixas das fotografias, ou em movimento, nos filmes e programas televisivos" (2005, p.133). Nesse aspecto, os quadrinhos, charges ou cartuns são tanto transmissores de informação, quanto agentes de lazer para grande número de pessoas que gosta deste tipo de leitura. Seu uso na escola permite aos alunos, na visão de Silva (2004), “ampliarem a capacidade de observação e de expressão, ao estimular a fantasia, ao despertar o prazer estético, senso de humor e a crítica, tornando o ato de ler uma atividade prazerosa e contribuindo para estabelecer o hábito saudável da leitura” (p. 24).

A utilização de tiras de quadrinhos e charges poderia ser mais intensa no ensino de Geografia, contudo o desconhecimento e a escassez de tempo do professor para se dedicar à seleção destes recursos são algumas das justificativas para limitação de seu uso. Esta oportunidade de reunir criatividade, criticidade, questionamento e diversão, com uma significação mais próxima dos alunos, pode resultar em maior envolvimento, interesse e mais reflexão no estudo de Geografia. Este trabalho de pesquisa almeja ser um meio de acesso a quadrinhos e charges como mais um recurso didático para mediar com competência o estudo de alguns elementos de Geografia, mais especificamente sobre espaço urbano, cidade e cidadania.

A seleção desse material se faz conforme as ponderações de vários autores, que, na atualidade, têm demonstrado preocupação com a relação ensino-aprendizagem de Geografia, propondo novas metodologias e perspectiva de análise (CASTROGIOVANI, 2001; CAVALCANTI, 2002; KAERCHER, 2001/2002; Moreira,1987; Oliveira, 1989; entre outros).

De acordo com Moreira (1987), "a Geografia que se ensina tem muita coisa a dizer que até agora não disse. Há outra Geografia” (p. 183). Como também, existem outras formas de se apreender Geografia e aprender a ensinar Geografia. 


\section{A charge e tiras de quadrinhos como linguagem alternativa na Geografia escolar}

É impossível a escola ignorar a carga de comunicações do dia a dia na vida das pessoas, tendo que aproveitar e se empenhar na função de questionar e buscar despertar o senso crítico dos estudantes para que possam ter condições de avaliar e de se apropriar de um olhar seletivo, com uma visão mais concreta do mundo atual. Conforme, Kenski,

as informações vêm de forma global e desconexa através dos múltiplos apelos da sociedade tecnológica. A escola precisa aproveitar essa riqueza de recursos externos, não para reproduzi-los em sala de aula, mas para polarizar essas informações, orientar as discussões, preencher as lacunas do que não foi apreendido, ensinar os alunos a estabelecer distâncias críticas com o que é veiculado pelos meios de comunicação. (2005, p. 143)

Em consonância com os argumentos citados, Cavalcanti (2002) comenta que a escola deve fazer uso de outras linguagens e de outras formas de expressão para procurar se aproximar mais da realidade dos educandos.

Desse modo, há que se destacar sua potencialidade para levar o aluno a perceber, por exemplo, a geografia no cotidiano, para fazer a ponte entre seu conhecimento cotidiano e o científico, para problematizar o conteúdo escolar e partir de outras linguagens e de outras formas de expressão (p. 83).

Na era digital, a internet, a charge (digital ou não), a TV e outros se legitimam como transmissores de informações fragmentadas. São informações que precisam ser aprofundadas e relacionadas ao que se está estudando ou se pretende estudar, pois trazem em seu contexto muitos elementos de Geografia, mas muitas vezes com análise superficial e até mesmo imbuída de determinadas ideologias (indução ao consumismo, à competição, à naturalização das desigualdades sociais, a vários tipos de preconceitos). Nesse sentido, Cavalcanti (2002) chama a atenção dizendo que

a cultura produzida neste mundo de tecnologias é repleta de informações geográficas. Os filmes, os desenhos, as charges, as fotografias, os slides, os anúncios de publicidade, os $C D$-ROMs, as músicas, os poemas representam freqüentemente, e das formas mais variadas o mundo, os lugares dos mundos os fenômenos geográficos, as paisagens. (p. 85)

Percebe-se que o conhecimento cultural é fundamental no ensino de Geografia para se compreender as informações e comunicações do cotidiano e reaproveitá-las como conteúdo de estudo. Almeida \& Ratts (2003) expli- 
cam que "se as culturas são plurais, a sua leitura também o é”(p. 7). Para esses autores, “... a geografia cultural é mais uma abordagem, uma maneira de interpretar a realidade...”(p. 9) e “...as sociedades criam códigos culturais, e as culturas dão a diversidade do mundo” (p. 7). Nesta perspectiva, a análise geográfica é plural e diversificada - a representação do espaço possui vários significados e análises. Existem, portanto, inúmeras maneiras de pensar, representar e interpretar o espaço geográfico, inclusive, formas alternativas de leituras deste espaço.

O uso de linguagem não convencional no estudo de Geografia articula-se com novas propostas de ensino. Para Reichwald (2004), "no bojo da renovação e dos novos caminhos trilhados, dialogar com as áreas do conhecimento, ler Geografia com base em textos variados das diferentes ciências, da mídia, do imaginário popular etc. é algo enfatizado com as mudanças dos anos 80 em especial” (p. 69).

A busca da apreensão da complexidade do mundo, mediada por diferentes representações, para ser capaz de escrevê-lo sob aspectos diversos, já é uma realidade na Geografia atual. Um olhar geográfico em diversas obras de arte existentes pode contribuir para tornar mais significativa a interpretação e aprendizagem dessa ciência no nível escolar. Nesse sentido, Reichwald (2004) sinaliza que "conhecendo o espaço do nosso aluno como expressão de valores culturais e políticos, além dos econômicos, ajuda significativamente na construção de uma geografia mais envolvente/próxima” (p. 70).

A análise geográfica, nas escalas: local, regional, nacional e mundial, pode se realizar por intermédio de diversos agentes culturais. Reichwald (2004) fala que a "trama da realidade do mundo só aproxima da sala de aula quando variamos as fontes de informação. Assim o livro didático não pode ser a única orientação na sala de aula” (p. 71). E mais adiante o mesmo autor salienta que a "mídia, jornal e televisão em especial, é instrumento que nos informa de maneira rápida sobre o mundo”( REICHWALD, 2004, p.72).

Claval (1997) deixa claro sobre a importância da comunicação e transmissão de informações, ao relatar que "os estudos da dimensão coletiva dos fatos culturais foi renovado pelos progressos da lingüística e da teoria da comunicação. A cultura é feita de informações que circulam entre os indivíduos e lhes permitem agir" (p. 94).

A difusão do conhecimento é facilitada com o domínio da escrita e da leitura, portanto, de acordo com Claval (1997), "a escrita permite fazer chegar as mensagens muito longe, o que favorece a difusão dos conhecimentos formalizados pela ciência e dos textos que veiculam religiões ou ideologias" 
(p. 112). Existem várias formas de escrever e se inscrever nos lugares do mundo e amplas são as formas de sua interpretação.

A leitura e a escrita podem ser permeadas pelo prazer (o riso), criatividade, criticidade e riqueza de análise encontradas nas tiras de quadrinhos, charges e cartuns, cuja compreensão inclui imagem e texto expresso pela escrita ou subentendido nas imagens. É a percepção do mundo pela observação do discurso, símbolos, sutileza das informações, com utilização de uma leitura agradável e, ao mesmo tempo, instigadora, como instrumento auxiliar de ensino, para decodificar e interpretar o espaço vivido.

Vergueiro (2005) reafirma: "E sem dúvida, os quadrinhos representam hoje, no mundo inteiro, um meio de comunicação de massa de grande penetração popular" (p. 7). Pois, mesmo com o aparecimento e concorrência de outros meios de comunicação, os quadrinhos continuam seduzindo um grande número de leitores fiéis. Esta atração é explicada por Cirne (2000): “a arte que não sabe seduzir não leva à paixão, não leva à reflexão” (p. 19).

Desde cedo as crianças criam desenhos para comunicar alguma idéia, como já o fazia o homem nas cavernas, estratégia semelhante à utilizada pelas histórias em quadrinhos, que com o uso de imagem gráfica comunica mensagens, muitas vezes, com ironias, irreverências e críticas. Segundo Cirne (2000), até os anos 60, a arte dos quadrinhos era considerada uma "arte menor", ou pior ainda, condenada por grande parte da sociedade (principalmente pais e professores) que a via com maus olhos, considerando sua leitura perniciosa aos mais jovens. Atualmente, é bastante aceita e se reconhece que contém símbolos e significados que podem permitir uma reflexão questionadora. É um elemento cultural, que, no entendimento de Cirne, pode apresentar a dimensão da poesia. Ele esclarece que "pensamos quadrinhos estética, política e culturalmente, acreditamos, inclusive, que poderemos pensá-los através de uma possível Poeticidade Libertária” (2000, p.15-6).

Com a diversificação da linguagem e com o exercício da imaginação, pode-se fazer a mediação de conteúdos escolares específicos, de acordo com os objetivos educacionais que se queira alcançar. E na visão de Vergueiro (2005b), "os quadrinhos podem ser utilizados em qualquer nível escolar e com qualquer tema” (p. 24). Sua escolha depende da análise do nível de conhecimento e capacidade de compreensão dos alunos, podendo ser usado para iniciar o tema, aprofundar algum conceito, concluir algum estudo, ou mesmo confrontar idéias, em séries escolares iniciais ou até mesmo em nível universitário. 
É um recurso de fácil acessibilidade e de baixo custo. E Silva (2005) aborda que "um outro aspecto importante na utilização de tais recursos é a sua proximidade com o cotidiano, pois estes são geralmente encontrados em jornais e revistas, tratando temas atuais, atemporais, divertindo e marcando épocas" (p. 1). É fundamental destacar que esse tipo de leitura e interpretação amplia a capacidade de compreensão da expressão cultural, e essa riqueza de análise proporciona uma maior reflexão questionadora das condições sociais, políticas e econômicas do mundo.

A leitura dos códigos visuais e verbais dos quadrinhos e similares pode despertar o interesse pelo assunto, dinamizar as aulas, motivar o debate, permitir uma análise reflexiva sobre várias questões, porém não deve ser o único recurso didático, devendo integrar e complementar outras atividades para mediar satisfatoriamente a compreensão do conteúdo do livro didático e de outros temas. Vergueiro(2005b) constata:“...deve-se buscar a integração dos quadrinhos a outras produções das indústrias editorial, televisiva, radiofônica, cinematográfica etc, tratando todos como formas complementares e não como inimigas ou adversárias na atenção dos estudantes" (p.27).

Nas tiras de quadrinhos e charges é possível estudar conteúdos da Geografia escolar como, por exemplo, categorias geográficas baseadas nas conceituações de geógrafos como Moreira (1987) e Correa (2000), que destacam: paisagem, região, espaço, lugar, território, ambiente e natureza. E também, a partir de conteúdos sugeridos por Cavalcanti (2002), que considera os conteúdos procedimentais, que “... dizem respeito àqueles temas trabalhados nas aulas com o intuito de desenvolver habilidades e capacidades para se operar com o espaço geográfico" (p. 38). E que ela os diferencia dos conteúdos atitudinais e valorativos, que "... referem-se à formação de valores, atitudes e convicções..." (p.40), os quais devem permear todas as disciplinas e setores da escola. Assim, podem-se analisar temas como globalização, questão urbana, ética ambiental, cartografia, cidadania, diversidade cultural e social, ética social, e outros.

Deste modo, considera-se que a interpretação das gravuras e do discurso facilita a compreensão e assimilação de informações. Muitas campanhas publicitárias utilizam quadrinhos para propagar idéias ou comunicar temas de utilidade pública. No entanto, nem sempre a linguagem é tão simples, podendo fazer uso de afirmações com duplo sentido ou de argumentos sutis para propagar ou ridicularizar algum acontecimento do cotidiano e que, às vezes, não é compreendido por todos.

Ao se decidir pelo exame das imagens e discursos encontrados em charges e tiras de quadrinhos relativos à Geografia da Cidade, é importante 
ressaltar que elas possuem informações de Geografia que perpassam todas as fases do Ensino Básico. E os elementos geográficos da cidade podem ser expressos de várias formas, como destaca Cavalcanti (2002) ao dizer que "os temas da cidade e do urbano são conteúdos que propiciam aos alunos possibilidades de confronto entre as diferentes imagens de cidade, as cotidianas e as científicas” (p.16). São concepções que podem ser percebidas em diversas manifestações da cultura, como: canções, poesias, reportagens, filmes, tiras de quadrinhos, crônicas, etc.

O ambiente, modo de vida, trabalho, moradia, trânsito e transportes, segurança, saúde, consumo e consumismo, segregação, lazer, educação, cultura, ética, comportamentos e valores urbanos são alguns dos elementos da dinâmica do espaço urbano/cidade e suas contradições, que podem ser representados nas produções culturais em questão (charges e tiras de quadrinhos). A decodificação da apresentação desses elementos de arte dimensiona uma percepção mais aguda, podendo ir mais a fundo na investigação sobre a cidade.

Cavalcanti (2001), ao comentar sobre a diferenciação de espaço urbano (conteúdo) e cidade (forma), ressalta que existe uma relação dialética entre essas categorias, que não se separam de forma absoluta, afirmando que "a cidade é um espaço geográfico, é um conjunto de objetos de ações, mas entendendo que ela expressa esse espaço, como lugar de existência das pessoas, não apenas como um arranjo de objetos, tecnicamente orientado" (p. 15). Cidade e espaço urbano constituem pares dialéticos de uma mesma realidade.

O processo de urbanização traz, em seu bojo, mudanças na relação sociedade-natureza e dos seres humanos entre si. No espaço urbano se (re) definem as relações sociais do cotidiano, que a sociedade concretiza no desenho da cidade. Assim, Carlos (2001) comenta que "os diversos elementos que compõem a existência comum dos homens inscrevem-se em um espaço; deixam aí suas marcas” (p. 11). O ser humano descreve de várias formas a história de sua existência, cujas interpretações são múltiplas.

Lefebvre (2006) argumenta que, a partir do uso da cidade, de seu consumo, se constitui a identidade e memória da sociedade urbana. Diante disso, se deduz que a cidade é um conceito que possui significados para os estudantes. Castellar (2006) contribui com essa discussão com considerações sobre a importância de o ensino ter significação aos alunos e que a cidade pode ser um projeto de educação geográfica.

A investigação proposta se realiza na concepção qualitativa, pela compreensão de permitir uma melhor percepção de análise da complexidade da realidade urbana e da cidade como conteúdo pedagógico. Na seleção 
do material pesquisado, não há grande preocupação com a quantidade e sim com a possibilidade de se refletir sobre a produção e reprodução do espaço urbano/cidade numa visão dialética e na sua contribuição na Geografia escolar. A pesquisa de campo é através do diálogo e comunicação entre pesquisadora, pesquisados e dos sujeitos pesquisados entre si (alunos e professores). Conforme a disposição dos professores e alunos, algumas turmas do Ensino Básico da rede pública foram escolhidas, para a experiência de utilização de alguns recursos didáticos selecionados. Com a observação da sua eficácia na mediação para a construção de conceitos consolidados referentes ao estudo de Geografia Urbana e Cidade, propõe-se um diálogo com maior profundidade para superar o senso comum com base no conhecimento científico e, com a intervenção e elaboração de colegas e professores, constituir coletivamente um novo texto de conceitos sobre a cidade.

Dois exemplos foram inseridos para ilustrar a capacidade da charge e tira de quadrinhos em fundamentar estudos da cidade ou de outros temas geográficos, inclusive viabilizar a produção de conceitos por meio da interdisciplinaridade.

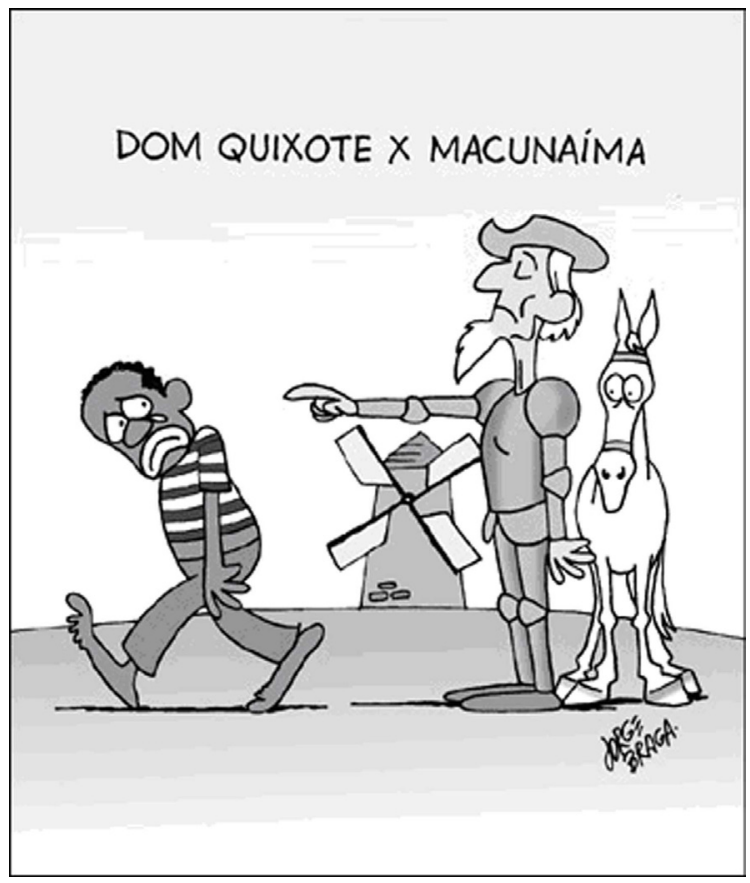

Figura 1 - Charge de Jorge Braga

Fonte: O popular, 12mar2008 

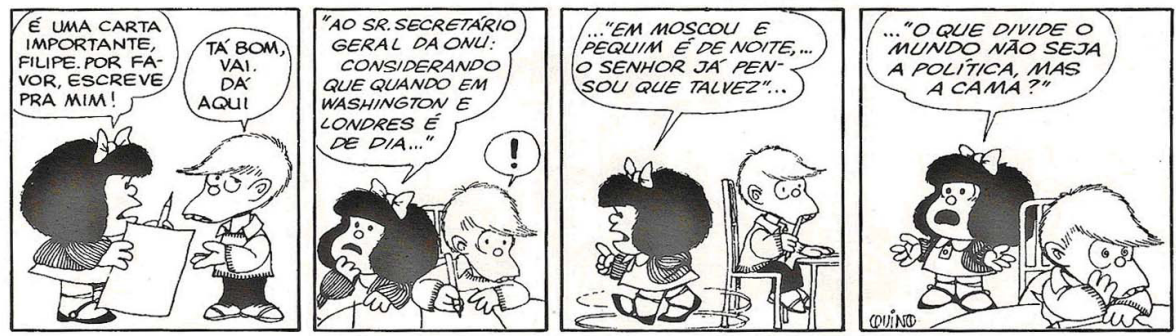

Figura 2 - Mafalda

Fonte: Quino. Toda Mafalda. São Paulo: Martins Fontes, 2003.

A figura 1 é uma charge que, para interpretá-la, necessita ser contextualizada. Macunaíma e Dom Quixote são personagens de dois clássicos da literatura brasileira e espanhola, respectivamente. Nela, ironiza-se e denuncia o incidente vivenciado recentemente por emigrantes brasileiros em território espanhol. É interessante ressaltar que a maioria dos brasileiros que migra, procura melhores oportunidades de vida, em outras cidades do país e do mundo.

Pelas expressões do desenho percebe-se o autoritarismo e evidencia a relação desigual entre os países do Sul e os do Norte. O mestiço Macunaíma descalço, a pé, humilhado, expulso por Dom Quixote, branco, calçado, a cavalo, superior. O próprio moinho forma a letra "xis", entre os dois: Espanha versus Brasil!

Na figura 2, por meio de um diálogo, que ocorre na casa de uma das personagens, permite a discussão sobre o porquê das diferenças de horário na Terra e proporciona questões sobre relações internacionais. É possível conversar sobre a Guerra Fria e sobre as novas regionalizações do mundo. Pode-se, ainda, relacionar tempo-espaço com o paralelo entre o modo de vida urbano atual e o do passado, quando atitude como escrever carta era um uso generalizado, além de outros comportamentos urbanos, hoje considerados ultrapassados.

As duas figuras podem ser relacionadas entre si. Ambas possibilitam o trabalho interdisciplinar com várias disciplinas, como Literatura e Língua Portuguesa, História, Sociologia, Filosofia. Afinal, deve-se pensar em desenvolver um trabalho mais coletivo e crítico na escola.

\section{Reflexões finais}

O objetivo principal dessa investigação é analisar uma produção cultural (charges e tiras de quadrinhos) popularizada pela divulgação nos 
meios de comunicação, para propor sua mediação como recurso didáticopedagógico, a fim de consolidar a produção de conhecimentos de estudos de conteúdos geográficos relativos à cidade e elaborar conceitos significativos no processo ensino-aprendizagem de Geografia.

É uma reflexão sobre essas expressões culturais e sua forma possível de contribuir, geograficamente, com o desenvolvimento do senso crítico, construção da cidadania. Dessa forma, demonstrar o seu potencial educativo, evidenciando que mesmo em linguagens onde o humor, a ironia, a criatividade estão presentes é possível exercitar a crítica, despertar consciência, aprofundar a análise de temas escolares, exemplificando: cidade e espaço urbano. Evidenciar que elementos encontrados no cotidiano são passíveis de participar com consistência da aprendizagem sobre a cidade.

Críticas construtivas serão bem vindas para contribuir na elaboração desse trabalho de pesquisa.

\section{Referências}

ALMEIDA, M. G. \& RATTS, Alecsandro J. P (orgs). Geografia - leitura culturais. Goiânia: Alternativa, 2003.

CARLOS, A. F. A. Espaço-tempo na metrópole. São Paulo: Contexto, 2001.

CASTROGIOVANI, A. C. E agora, como fica o ensino da Geografia com a globalização? In: CASTROGIOVANI, A. C., et al ( orgs.) Geografia em sala de aula: práticas e reflexões. $3^{\mathrm{a}}$ ed. Porto Alegre: Editora da Universidade/UFRGS/AGB-Seção Porto Alegre, 2001.

CASTELLAR, S. M. V. A cidade e a cultura urbana na Geografia escolar. Boletim Paulista de Geografia, São Paulo, n. 85, p. 95-111, 2006.

CAVALCANTI, L. de S. Geografia da Cidade. Goiânia: Alternativa, 2001.

. Geografia e práticas de ensino. Goiânia: Alternativa, 2002.

CLAVAL, P. As abordagens da Geografia Cultural. In: CASTRO, Iná Elias de, et al (orgs.). Explorações geográficas. Rio de Janeiro; Bertrand Brasil, 1997.

CIRNE, M. Quadrinhos, sedução e paixão. Petrópolis, RJ: Vozes, 2000.

CORRÊA, R. L. Espaço: um conceito-chave da Geografia. In: CASTRO, I. E., et al (orgs.). Geografia: conceitos e temas. $2^{\mathrm{a}}$ ed. Rio de Janeiro: Bertrand Brasil. 2000.

Jornal - O Popular. Goiânia, Go

KAERCHER, N. A. Estudos Sociais: reflexões, conflitos e desafios. In: CASTROGIOVANI, A. $\mathrm{C}$, et al ( orgs.) Geografia em sala de aula: práticas e reflexões. $3^{\mathrm{a}}$ ed. Porto Alegre: Editora da Universidade/UFRGS/AGB-Seção Porto Alegre, 2001. 
. O gato comeu a Geografia crítica? Alguns obstáculos a superar no ensino-aprendizagem de Geografia. In: PONTUSCHKA, Nídia nacib \& OLIVEIRA, Ariovaldo Umbelino (orgs). Geografia em perspectiva. São Paulo: Contexto, 2002.

KENSKI, V. M. O ensino e os recursos didáticos em uma sociedade cheia de tecnologia. In: VEIGA, I. P. A. (org.). Didática: o ensino e suas relações. 9ª ed. Campinas, SP: Papirus, 2005.

LEFEBVRE, H. O direito à cidade. $4^{\mathrm{a}}$ ed. São Paulo: Centauro Editora, 2006.

MOREIRA, R. O discurso do avesso (para a crítica da Geografia que se ensina). Rio de janeiro; 1987.

MORETTI, F. Qual a diferença entre charge, Cartum e quadrinhos? Disponível em: <http:// ccghumor.com.br>. Acesso em 18 de set. de 2006.

OLIVEIRA, A. U. (org.). Para onde vai o ensino de Geografia? São Paulo: Contexto, 1989.

QUINO. Toda Mafalda. São Paulo: Martins Fontes, 1993.

REICHWALD JR., G. Leitura e escrita na geografia ontem e hoje. In: NUNES, Conceição Bitencourt, et al (orgs.). Ler e escrever - compromisso de todas as áreas. $6^{\mathrm{a}}$ ed. Porto Alegre: Ed. Da UFRGS, 2004.

SILVA, D. de B. M. A charge em sala de aula. Disponível em: < http;//filologia.org.br $>$. Acesso em 08 de out. de 2005.

SILVA, J. R. F. O espaço geográfico expresso nas histórias em quadrinhos: uma experiência com Chico Bento. 2004. Dissertação (Mestrado em geografia). Universidade Estadual de São Paulo, Presidente Prudente, SP, 2004.

VERGUEIRO, V. Uso das HQS no ensino. In: RAMA, Ângela \& VERGUEIRO, Valdomiro (orgs.). Como usar as histórias em quadrinhos na sala de aula. São Paulo: Contexto, 2005.

. Uso das HQS no ensino. In: RAMA, A. \& VERGUEIRO, V. (orgs.). Como usar as histórias em quadrinhos na sala de aula. São Paulo: Contexto, 2005b.

Eunice Isaias da Silva - Doutoranda do programa de pós graduação da

Lana de Souza Cavalcanti - Professora Adjunta do Departamento Instituto de Estudo Socio - Ambientais da Universidade Federal de Goiás 
